\title{
Marguerite Yourcenar, «Persévérer dans l'être». Correspondance 1961-1963 (D’Hadrien à Zénon, III)
}

\section{Susanna Bonomi}

\section{(2) OpenEdition}

1 Journals

\section{Edizione digitale}

URL: http://journals.openedition.org/studifrancesi/1624

DOI: 10.4000/studifrancesi. 1624

ISSN: 2421-5856

\section{Editore}

Rosenberg \& Sellier

\section{Edizione cartacea}

Data di pubblicazione: 1 novembre 2014

Paginazione: 636-637

ISSN: 0039-2944

\section{Notizia bibliografica digitale}

Susanna Bonomi, « Marguerite Yourcenar, «Persévérer dans l'être». Correspondance 1967-1963

(D'Hadrien à Zénon, III) », Studi Francesi [Online], 174 (LVIII | III) | 2014, online dal 01 novembre 2014 consultato il 18 septembre 2020. URL : http://journals.openedition.org/studifrancesi/1624 ; DOI : https://doi.org/10.4000/studifrancesi.1624

Questo documento è stato generato automaticamente il 18 settembre 2020.

\section{(c) 9 (i) $\Theta$}

Studi Francesi è distribuita con Licenza Creative Commons Attribuzione - Non commerciale - Non opere derivate 4.0 Internazionale. 


\title{
Marguerite Yourcenar, «Persévérer dans l'être». Correspondance 1961-1963 (D’Hadrien à Zénon, III)
}

\author{
Susanna Bonomi
}

\section{NOTIZIA}

MARGUERITE YOURCENAR, «Persévérer dans l'être». Correspondance 1961-1963 (D'Hadrien à Zénon, III), texte établi et annoté par Joseph BRAMI et Rémy POIGNAULT, avec la collaboration de Maurice DELCRoIX, Colette GAUDIN et Michèle SARDE, Paris, Gallimard, 2011, pp. 514.

1 Continua il lavoro degli abituali curatori sulla corrispondenza della grande scrittrice belga iniziato nei tre volumi precedenti: Lettres à ses amis et quelques autres (1995), D'Hadrien à Zénon, Correspondance 1951-1956 (2004) e "Une volonté sans fléchissement». Correspondance 1957-1960 (2007). Questo quarto volume è dedicato all'analisi delle lettere scritte da Marguerite Yourcenar tra il 1961 e il 1963. Il materiale di partenza è sempre lo stesso: le copie, dattiloscritte o manoscritte, delle missive di Marguerite Yourcenar da lei stessa consegnate alla Houghton Library della Harvard University. Le scelte editoriali sono molto chiare e sono le stesse dei precedenti volumi: i testi sono presentati in ordine cronologico, quelli già contenuti nella prima raccolta sono segnalati al giusto posto senza però essere nuovamente riportati, le lettere scritte da Marguerite Yourcenar in altre lingue (italiano o inglese) sono state tradotte in francese. Come per gli altri tre volumi colpisce la monodirezionalità di questa corrispondenza, che non ha nulla della dialogicità dello scambio epistolare: volutamente, sono riportate solo le lettere scritte da Marguerite Yourcenar e il lettore può solo cercare di ricostruire l'altro lato della corrispondenza da quanto trapela dagli accenni presenti nelle parole della scrittrice belga.

2 Gli anni presi in esame in questa raccolta rappresentano un momento cruciale nella vita dell'autrice, che raggiunge in questo frangente la sessantina. È l'epoca della 
maturità, dell'affermazione personale e artistica, ma non è ancora giunto il momento di ritirarsi, anzi. Mai come in questo momento che emerge chiaramente dalle lettere l'autrice è occupée dal suo lavoro: tanti sono i progetti ed i testi in elaborazione. Marguerite Yourcenar sta ultimando lo studio su Piranesi, lavora alla pubblicazione dei saggi su Agrippa d'Aubigné, sul castello di Chenonceau e sull'Historia Augusta, che poi raccoglierà insieme ad altri in Sous bénéfice d'inventaire (che le vale nel 1963 il Prix Combat), raccoglie materiale per i due saggi su Santa Elisabetta di Ungheria e su San Biagio, rivede il testo su Pindaro, si occupa della traduzione dei Negro Spirituals, riprende in mano le Nouvelles orientales per ripubblicarle, rielabora per il teatro Denier du rêve, lavora a Qui n'a pas son Minotaure? e alla prefazione di Le Coup de grâce e all' Alceste, monitora le pubblicazioni all'estero in traduzione delle sue opere, si occupa di procurare le fotografie per un'edizione americana illustrata dei Mémoires d'Hadrien e rimaneggia incessantemente la bozza di quella che diverrà L'CEuvre au noir. Attraverso le lettere emerge come l'autrice si occupi, e si preoccupi, di tutte le fasi che accompagnano un suo testo dal concepimento alla pubblicazione; le lettere sono un modo per riflettere sul mestiere dello scrittore, così come lo concepisce Marguerite Yourcenar. Avere a che fare con questa scrittrice così attenta al suo "laboratorio di scrittura", come era solita definirlo lei stessa, non è sempre facile e sono numerose le missive in cui ella si confronta, per non dire si scontra, con editori, direttori di riviste e compagnie teatrali per i motivi più svariati, siano essi di natura contingente (economici o contrattuali) o di natura artistica (correzione delle bozze, mancato rispetto della volontà dell'autrice od offerta di collaborazione rifiutata da una parte o dall'altra). Ci sono poi le lettere in cui Marguerite Yourcenar è chiamata a fare il critico letterario: talvolta delle proprie opere, in risposta a giuste o errate osservazioni dei suoi lettori, talvolta di opere altrui, qualora le vengano sottoposte. Sporadici sono invece, come sempre, i rapporti con il mondo intellettuale suo contemporaneo, anche se dalle lettere emerge chiaramente come Marguerite Yourcenar fosse un'attenta osservatrice della realtà circostante.

3 Non solo progetti letterari, tuttavia. Anche se i viaggi sono considerevolmente ridotti in questi anni di intenso lavoro letterario; la prima metà del 1961 vede l'autrice dei Mémoires d'Hadrien impegnata in una serie di conferenze negli Stati Uniti e numerose missive sono dedicate alla definizione della tempistica degli spostamenti, delle tematiche da affrontare e delle spese da rimborsare. Ci sono infine alcune, rare lettere strettamente personali, piccole perle da cui trapela l'essenza più intima della donna di Petite Plaisance.

4 Questo quarto volume, il terzo che conduce, come recita il titolo, "d'Hadrien à Zénon", scatena nel lettore, studioso yourcenariano o meno, il desiderio di leggere il seguito di questa corrispondenza, che non si discosta nell'uso magistrale della parola dalla bellezza delle più celebri opere letterarie di Marguerite Yourcenar. 